redevelopment of Hubrecht's view that vertebrates evolved from neriertines; a view "more or less ridiculed by zoologists", as Willmer challengingly admits.

He presents the nemertine case with the expected wealth of detail, but weakens it by not subjecting it to a sufficiently rigorous analysis and by introducing a substantial element of special pleading. Moreover, when an argument is deliberately based primarily upon considera. tions of cellular organization, it is difficult to give proper weight to other aspects of animal design and evolution. Thus, the widely held view that vertebrates arose from an echinoderm/chordate (deuterostome) line is summarily dismissed, without benefit of discussion, on the ground that it depends on "somewhat unlikely reasoning" (as though no such charge could lie against the nemertine theory), while the suggested relationship of nemertines to protochordates is discussed with reference to the Entero. pneusta, but with no mention of the Pterobranchia. Yet the sessile habit and ciliary feeding of the latter are very relevant, especially in conjunction with the presence of a temporary post-anal tail in the larva of Saccoglossus horsti.

The argument runs into no less trouble when histological detail is being considered. Willmer finds it curious that the principal lateral nerves of nemertines are not present in enteropneusts, but it would surely be surprising if they were, considering that the intraepidermal nerve net of the latter is more primitive in organization than the centralized system of flatworms. And the rigours of zoological analysis are wholly swept aside with the suggestion that the insulin-secreting follicles of Langerhans of the lamprey larva may be vestigial nephridia; a thought (admittedly subsidiary to the principal argument) evoked in the author by reflexions on the existence of enteronephridia in some highly specialized earthworms.

Willmer has designedly produced an "unorthodox and unusual" book, intended to provoke interest and investigation and not to be a comprehensive text. It certainly transmits his enthusiasm to his readers, and will give zoologists lively material for many an honours seminar.

E. J. W. BARRINGTON

\section{ASPECTS OF REPTILES}

\section{Traité de Zoologie}

Anatomie, Systématique, Biologie. Publié sous la direction de Pierre P. Grassé. Tome XIV: Reptiles, fascicule 2 : Caractères Généraux et Anatomie. Pp. $680+x x x i i$. (Masson: Paris, 1970.) 225 francs.

For many years there were very few available texts making comparative surveys of aspects of reptilian biology, and several of these were rather old. This, the first of two reptile "fascicules" in Grassé's Traité, is the latest of several works to appear in the past few years. It is nevertheless immediately welcome, for it covers aspects for which there is no other recent survey available.

The title page indicates that the volume is on anatomy, but there are chapters on locomotion and snake venom and in other chapters there are many welcome references to biochemistry and physiology. Otherwise, skin, skeleton, musculature, venom apparatus, nervous system, sense organs, blood and vascular system, respiratory and alimentary systems are covered. Several of the chapters are by persons who have carried out research in the areas concerned and these have many original figures. Most of the chapters, however, are compilations from the literature and have borrowed illustrations, but are no less useful as sources of information on that account. As elsewhere in the Traité, all the illustrations are redrawn giving a pleasing uniformity of style. This sometimes has draw. backs, however; Phisalix's figure of the skull of Coluber hippocrepis (Fig. 92) has some inaccuracies, bears an out of date name, and does not clearly illustrate some of the well made points in the text which it accompanies.

Few of the references are later than 1966; this is, no doubt, an indication of the time required to assemble and edit twenty-one contributions. The chapter on the eye has some lapses, perhaps because of the death of the author before completion; I was nevertheless astonished to find no reference to the books by Franz, Walls or RochonDuvigneaud (the author of the chapter!), all published more than 25 years ago.

In several respects the book should have been more carefully edited. I was rather frequently irritated at being unable to find in the bibliography a work cited in the text. Lapses in the spelling of the names of authors and reptiles are so common that anybody using the work as a source of information would be well advised to check these. For example, a snake found in France is variously cited and indexed as Natrix maura and Tropidonotus viperinus, almost side by side on p. 252; there are three spellings of Thelotornis in the text, two repeated in the index and none of them is correct. Feylinia is assigned to the family Dibamidae on pp. 415 and 417, a placement which I have not seen before.

In general, the five principal groups of living reptiles are characterized and compared, and variations at family and lower levels are indicated but not discussed. The book gives a sound introduction to a wide range of topics. Every institution in which there is an interest in reptiles should have a copy on the library shelf-at more than $6 d$ per page I doubt that it will find its way onto many private bookshelves.

GaRTH UNDERWOOD

\section{ANIMAL GROWTH HORMONES}

\section{Control of Growth and Metamorphosis}

Part 2 of Animal Hormones: A Comparative Survey. By P. M. Jenkin. (International Series of Monographs in Pure and Applied Biology: Zoology Division, Vol. 47.) Pp. xviii +383 . (Pergamon: Oxford and New York, August 1970.) 100s; $\$ 13.50$.

IN 1962 Penelope Jenkin published the first part of her "Comparative Survey of Animal Hormones"; but she was overtaken by the growth of published knowledge and was able to cover only "Kinetic and Metabolic Hormones". Now, after eight years, part two has appeared. This was intended to deal with all morphogenetic hormones-but in the event has had to be limited to hormones concerned in the control of growth, moulting and metamorphosis. But it forms a self-contained whole. Although the author assumes familiarity with part one, and provides many cross-references to this, it is none the less a valuable book in its own right. As in the earlier volume, the author has added enormously to her labours by comparing the hormonal regulation, for every topic that comes up for consideration, throughout representatives of the entire animal kingdom, so far as that is known. This has taxed the author; and it taxes the reader-but it was well worth doing.

In the description of the moulting of arthropods much weight is attached to "apolysis", the "freeing of the epidermal cells from the old exoskeleton", as the crisis of moulting. Apolysis is a useful self-explanatory term-so long as it is borne in mind that it is an abstraction. The first sign of moulting is the active synthesis of nucleoproteins in the epidermal cells which usually, but not always, leads on to mitosis. So far as a given cell is concerned, mitosis necessitates separation from the cuticle; but mitosis begins at different times in different regions of the epidermis. Separation is such a gradual process that it is impossible in practice to pin down the time of apolysis. And yet the "actual instar" is here defined as the form of the arthropod over the period from one apolysis to the 